\title{
A Study of Imitation Ability in People with Trisomy 21
}

\author{
André Frank Zimpel and Alfred Christoph Röhm \\ Centre for Neurodiversity Research (CNDR) Hamburg/Eppendorf, University of Hamburg, Hamburg, Germany
}

\begin{abstract}
Since the first description of Down syndrome, imitation has been a reputed strength of persons with trisomy 21. The question is: How many elementary movements can persons with trisomy 21 imitate simultaneously and successively? As a baseline, we developed elementary movements that are easy to imitate separately. They are combined such that there are no recognizable repetitions or other regular patterns. In all of the 713 test subjects there was a limit to the number of correctly imitated elementary movements. Whereas neurotypical subjects reached their limit by imitating four elementary movements, persons with trisomy 21 could imitate only two elementary movements. Diagnostic and learning methods currently need to be reassessed, because they do not consider these special imitation limits.
\end{abstract}

Keywords: Down syndrome, trisomy 21, kinesthetic dyspraxia, simultaneous dysgnosia, imitation

\section{Studie zur Imitationsfähigkeit von Menschen mit Trisomie 21}

Zusammenfassung: Imitation gilt seit der Erstbeschreibung des Down-Syndroms als eine vermeintliche Stärke von Menschen mit Trisomie 21. Die Frage ist: Wie viele Elementarbewegungen können Menschen mit Trisomie 21 simultan und sukzessive imitieren? Deshalb entwickelten wir als Ausgangsbasis Elementarbewegungen, die einzeln mühelos zu imitieren sind. Sie sind so kombiniert, dass sie durch keine Wiederholungen oder andere regelmäßigen Muster verbunden sind. Die Anzahl der fehlerfrei reproduzierten Elementarbewegungen wies bei allen der 713 am Experiment Teilnehmenden eine Grenze auf. Neurotypische Personen erreichen sie beim Imitieren von 4 Elementarbewegungen, Menschen mit Trisomie 21 bei der Imitation von 2 Elementarbewegungen. Diagnostik und Lehrmethoden müssen gegenwärtig neu durchdacht werden, weil sie diese besonderen Grenzen der Imitation nicht berücksichtigen.

Schlüsselwörter: Down Syndrom, Trisomie 21, kinästhetische Dyspraxie, Simultan Dysgnosie, Imitation

\section{Introduction}

Lejeune, Gautier, and Turpin (1959) proved that trisomy 21 (Down syndrome - descripted by J.L. Down in 1866) is caused by an extra copy of chromosome 21 (HSA21). A restricted region of HSA21, commonly referred to as Down syndrome critical region (DSCR), might be responsible for the different phenotypes that characterize persons with trisomy 21.

Montoya et al. (2014) obtained expression profiles of 19 DSCR genes in 42 brain substructures, from gene expression values available at the database of the human brain from the Brain Atlas of the Allen Institute for Brain Sciences (http://human.brain-map.org/). They registered the highest levels of gene expression at the basal ganglia (caudate nucleus, putamen) and limbic system (nucleus accumbens, hippocampus) among the central areas of cerebral cortex: "That previously identified brain structures play a crucial role in the learning process, in different class of memory and in motor skills" (Montoya et al., 2014, pp. 154-156).
Down (1866, p. 261) characterized the memory and motor skills of the phenotype that was named for him as follows: "They have considerable power of imitation." This strength of imitation of persons with Down syndrome (with trisomy 21) has been studied and confirmed multiple times in the pertinent literature. König (1959, p. 191), a pediatrician and special-needs educator, writes the following: "They show a great talent for imitating other people." Asperger (1965, p. 92), also a pediatrician and special-needs educator, describes similar phenomena, which he considers to be the ability to affect greater intelligence than is actually present: "They are incredibly adept at imitating appearances or the gestures of an action when reading a newspaper or writing, for example, they are able to nod quite 'wisely,' and although they are, of course, not in the least able to perform the action in reality, they often make a rather sweet impression and are thus usually thought by family members to be more intelligent than they really are."

Asperger's evaluation illustrates that imitation was often formerly trivialized as a primitive form of learning in 
the sense of "aping" someone. On the whole, however, it is clear that imitation is obviously a reputed (but often underestimated) strength of persons with trisomy 21.

Our studies demonstrate that the visual scope of attention of persons with trisomy 21 is limited, a limitation that incidentally also applies to the acoustic and haptic scope of attention. The differences are highly significant (Röhm, 2016, pp. 135-138; Zimpel, 2013, 2016, pp. 112-134).

That is why our supposition is based on the speculation that the attentional scope would be the identical independent of the sensory modalities. If this were the case, the attentional scope of persons with trisomy 21 would also have to be limited regarding the perception of the stretch receptors (proprioception, kinesthesia, and deep sensibility). This would result in limiting the ability of persons with trisomy 21 to imitate, which in turn would affect not only their ability to repeat words, but also their ability to imitate movements, as it is known from kinesthetic dyspraxia.

Our hypothesis is therefore: People with trisomy 21 reach the limit of their ability to imitate a series of elementary movements that increase in number sooner than persons without the syndrome. Empirically confirming this hypothesis would then disprove the thesis that "imitation learning is a strength of persons with trisomy 21." Their strengths, too, would then have to be sought in types of emulation learning. The didactic consequences would be far-reaching.

\section{Hypothesis on the Ability to Imitate}

We therefore presume that trisomy 21 may also narrow the kinesthetic attentional scope. Our hypothesis comprises three parts:

- The ability to exactly imitate a set of elementary movements following a complete presentation of the composite movement decreases more quickly in persons with trisomy 21 (test group) as the number of elementary movements increases than it does in persons without trisomy 21 (control group).

- The ability to exactly imitate a set of elementary movements during the presentation of the composite movement decreases more quickly in persons with trisomy 21 (test group) as the number of elementary movements increases than it does in persons without trisomy 21 (control group).

- The ability to exactly imitate a set of elementary movements following the presentation of the composite movement - which leaves a visible mark - decreases more quickly in persons with trisomy 21 (test group) as the number of elementary movements increases than it does in persons without trisomy 21 (control group).

\section{Methods}

\section{Experimental Procedure}

The three hypotheses were evaluated using three sets of tests:

- Test Set 1: Imitation without memory aids following the presentation of a series of elementary movements (body percussion),

- Test Set 2: Imitation without memory aids during the presentation of a series of elementary movements (dancing hands), and

- Test Set 3: Imitation with memory aids following the presentation of a series of elementary movements (drawing).

\section{Procedure for Test Set 1 (Body Percussion):}

Test Set 1 comprises 20 different imitation experiments, which in turn consist of varying numbers of elementary movements, for example, clapping hands and stomping feet, etc. The task is to imitate these elementary movements without memory aids following the presentation.

The imitation phases should not begin until after each of the individual experiments has been presented. We do this to ensure that the perceived movement sequences for each experiment have been stored in their entirety in the working memory and can subsequently be reproduced correctly.

The varying degrees of difficulty of the individual imitation experiments correspond to the number of elementary movements in this experiment. They shift randomly between one and seven elementary movements. An example of an experiment consisting of four elementary movements is shown in Illustration 2. The complete Test Set with 20 different imitation experiments consists of in each case three experiments with one, two, four, and five elementary movements, four experiments with three elementary movements and two experiments with six to seven elementary movements. This random order was maintained for all of the experiments (Figure 1).

The procedure for the imitation experiment in the Test Set 1 (body percussion) was standardized as follows: During the presentation of the imitation demonstration, the test subjects sat in front of a monitor. The movements were presented as a video on a large monitor or projected onto a screen (Figure 2).

The task is to watch the movements, memorize them exactly in sequence, and then perform them in the correct order. A tone sounds immediately following the presentation as a signal that the demonstration has been completed and the imitation phase of the individual experiment has begun. Each video is only played once (Figure 3). 


\section{Body Percussion}

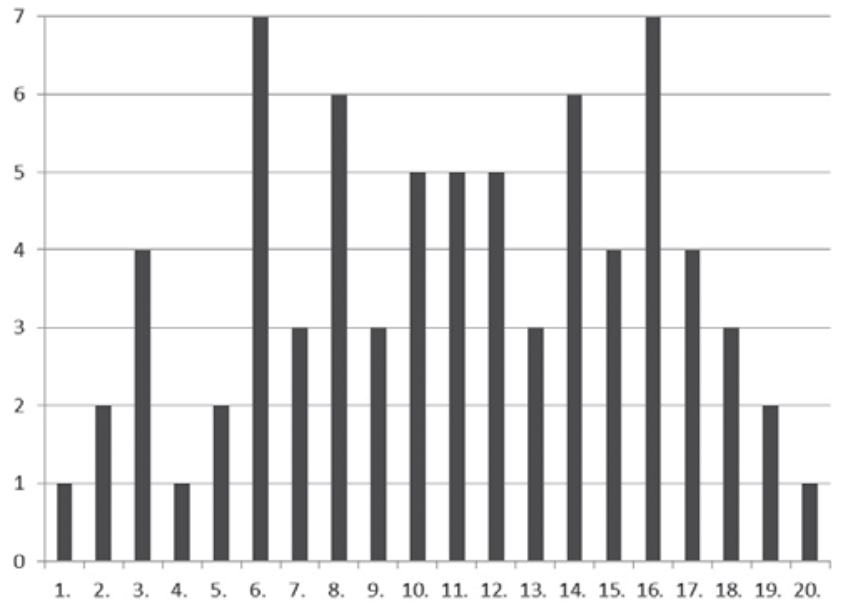

Figure 1. Random change in difficulty level of the individual imitation experiments between one and seven elementary movements. Abscis sa: Number of imitation experiments with different numbers of elementary movements for body percussion; ordinate: Number of elementary movements (level of difficulty).

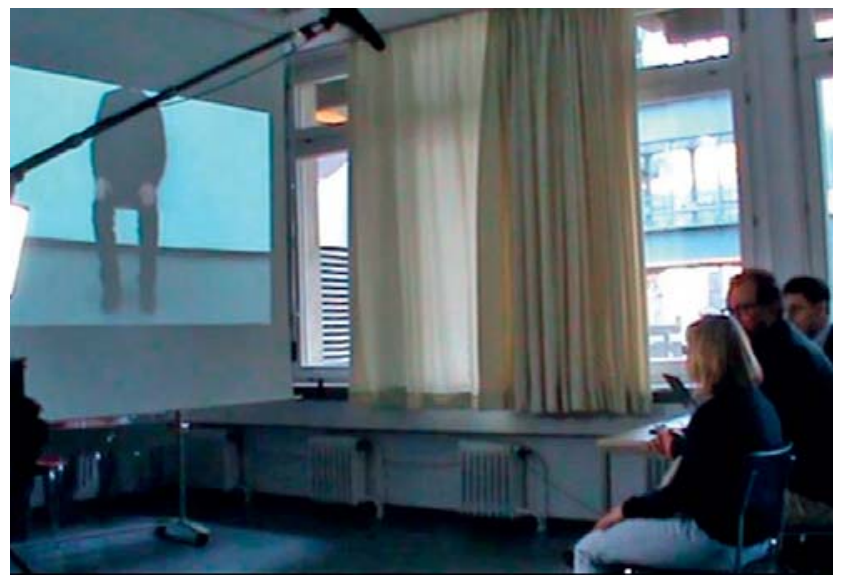

Figure 2. Imitation test (body percussion) with a 23-year-old young woman from the test group.
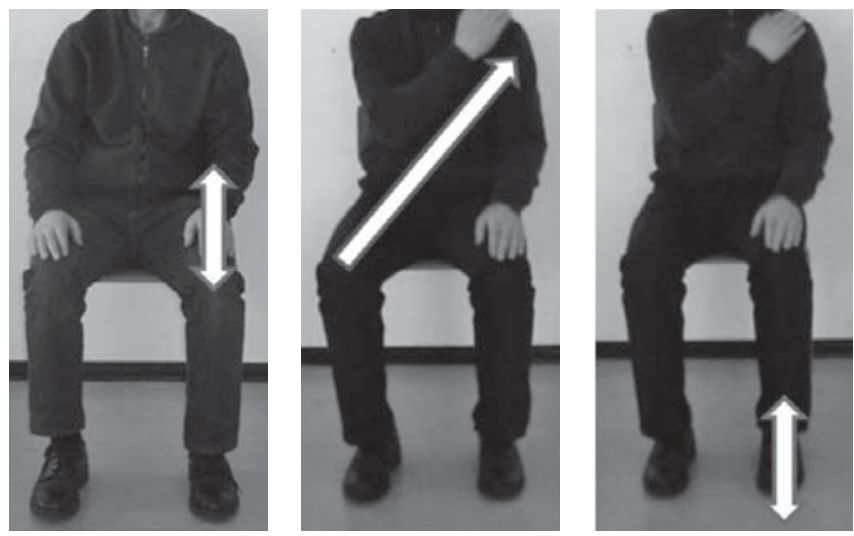

Procedure for Test Set 2 (Dancing Hands):

In Test Set 2, the test candidates imitate the movement patterns as they are being presented. The task is to imitate these elementary movements without memory aids during the presentation (Figure 4).

In this case there are 13 different imitation experiments using hands and arms. Examples: outward and inward rotation of the hands, flexion and extension of the fingers, and using the hands to knock on the surface of the table (Figure 6).

The difficulty in performing the imitation exactly increases as the number of elementary movements that have to be kept in mind simultaneously increases. The varying degrees of difficulty of the individual experiments are equal to the number of elementary movements in this experiment. They shift randomly between one and seven elementary movements. An example of an experiment consisting of three elementary movements is shown in Illustration 4.

The complete Test Set 2 with 13 different imitation experiments consists of in each case four experiments with one elementary movement, three experiments with two elementary movements, two experiments with three elementary movements, and one experiment with four to seven elementary movements. They change according to the following random order. The random order was also maintained for all experiments (Figure 5). This task is to imitate the elementary movements seen on the video as immediately as possible (Illustration 3).

According to the hypothesis, the people in the test group (trisomy 21) should have greater difficulties performing the imitations than the control group. This should already be apparent with fewer elementary movements than have to be performed along with the video.

\section{Procedure for Test Set 3 (Zigzag Lines):}

The task is to imitate elementary movements (drawing) with memory aids following the presentation. The memory aid in Test Set 3 consists of visible markings left as

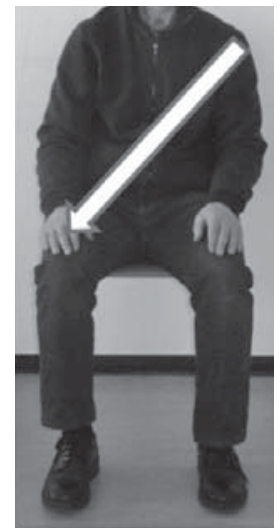

Figure 3. Imitation experiment from the body percussion Test Set with four elementary movements. The four pictures are parts of a progression of four video sequences. The arrows show the movement demonstrated in the video. Picture 1: Hand pats the knee on the same side of the body. Picture 2: Hand touches the shoulder on the opposite side of the body. Picture 3: Foot stomps on the floor on the same side of the body. Picture 4: Hand moves from the shoulder on the opposite side of the body to the knee on the same side. 
a result of the predrawing and copying of zigzag lines (Figure 7).

In Test Set 3 there are eight imitation experiments that, as in the previous experiments, differ in the number of elementary movements. As in the Test Set 1 (body percussion), the imitation phase should not begin until after the conclusion of the presentation of each of the individual experiments. The difference, however, between this and both of the previous test sets is that the movement is performed with a pen and leaves visible marks on the paper (zigzag lines). These marks should make the imitation easier. For this experiment one elementary movement is considered to be one segment of the zigzag line. The number of predrawn segments in the individual imitation experiments varies between one and seven. An additional experiment has 15 segments (Figure 8).

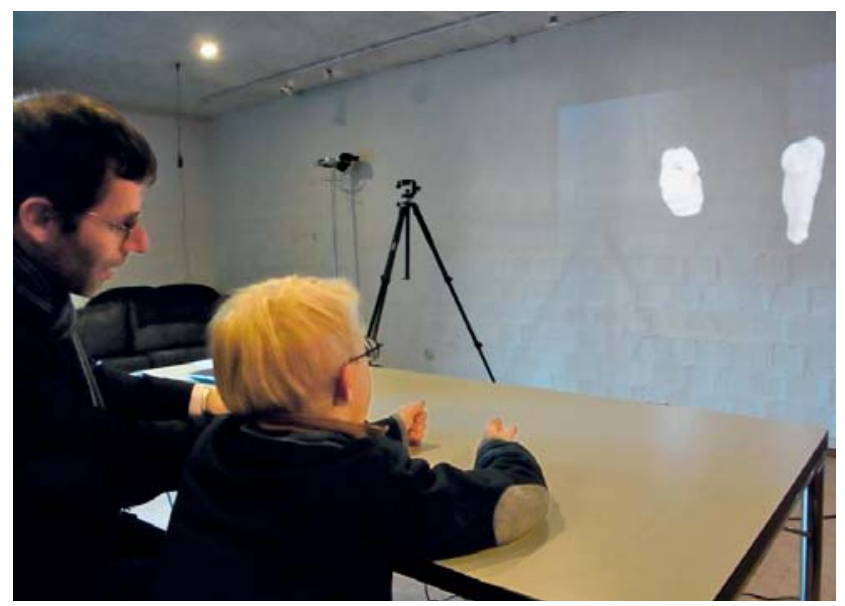

Figure 4. Imitation test (dancing hands) with a 6-year-old boy from the test group.
After the test administrator uses a pen to predraw a zigzag line on a piece of paper, the test subject copies it as exactly as possible (Figure 9). There is no time limit. According to the hypothesis, the test group should have greater difficultly than the control group correctly copying the longer zigzag lines.

\section{Participants}

A total of 703 persons took part in the imitation study (Table 1). A prerequisite for participating in the test series was the subject's ability to imitate something and his or her motivation to do so as exactly as possible.

There were 316 people in the test group (with trisomy 21) and 387 people in the control group (without trisomy

\section{Dancing Hands}

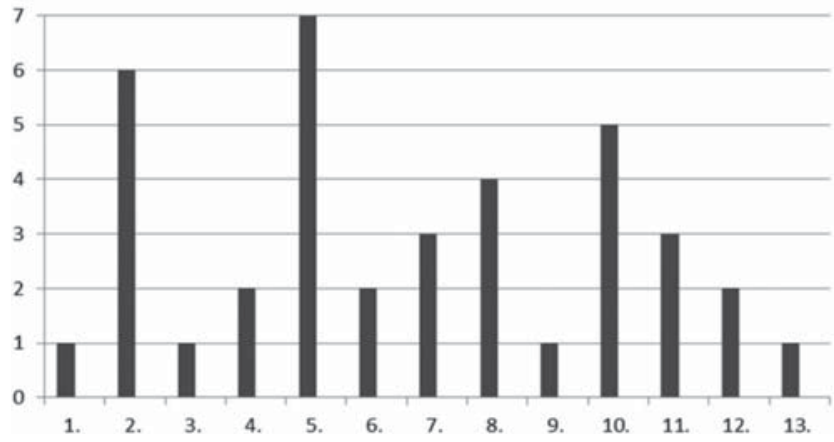

Figure 5. Change in difficulty level of the individual imitation experiments between one and seven elementary movements. Abscissa: Number of imitation experiments with different numbers of elementary movements for the Test Set dancing hands; ordinate: Number of elementary movements (level of difficulty).
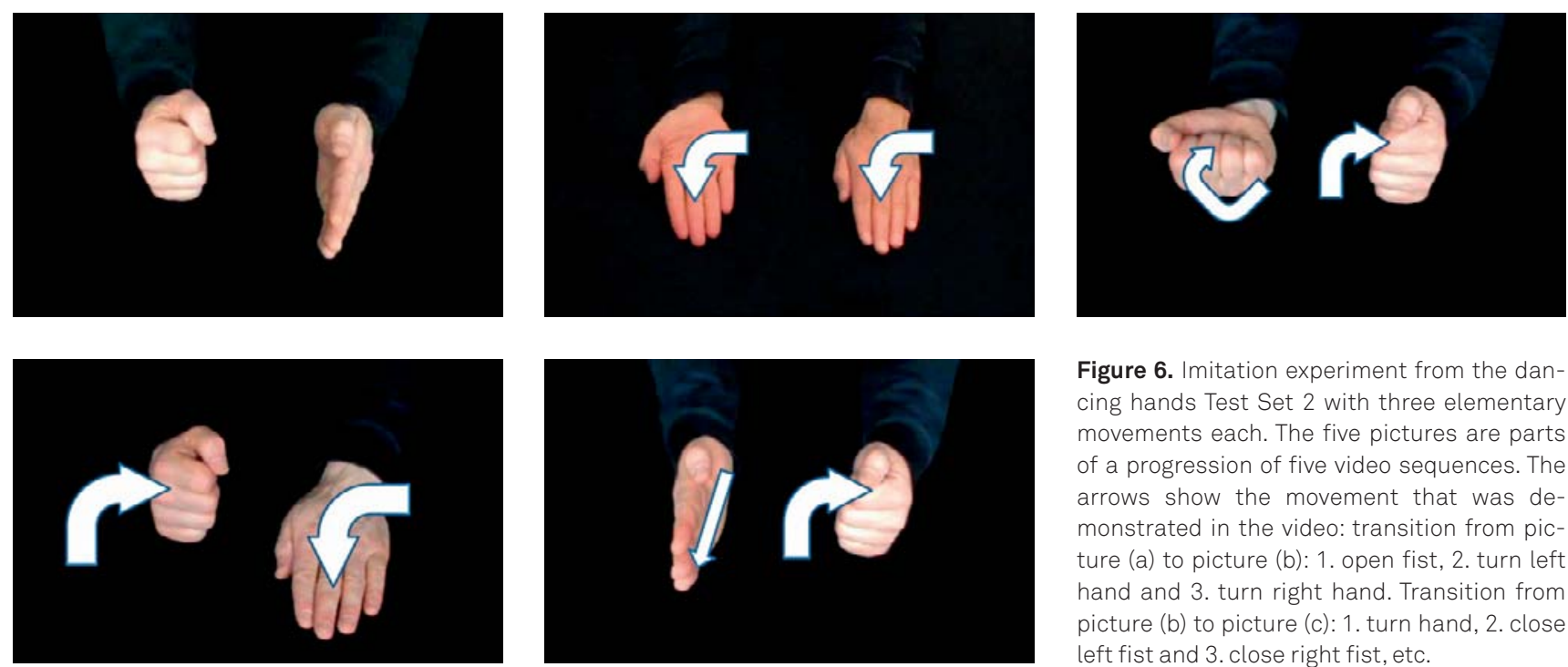

Figure 6. Imitation experiment from the dancing hands Test Set 2 with three elementary movements each. The five pictures are parts of a progression of five video sequences. The arrows show the movement that was demonstrated in the video: transition from picture (a) to picture (b): 1. open fist, 2. turn left hand and 3. turn right hand. Transition from picture (b) to picture (c): 1. turn hand, 2. close left fist and 3. close right fist, etc. 

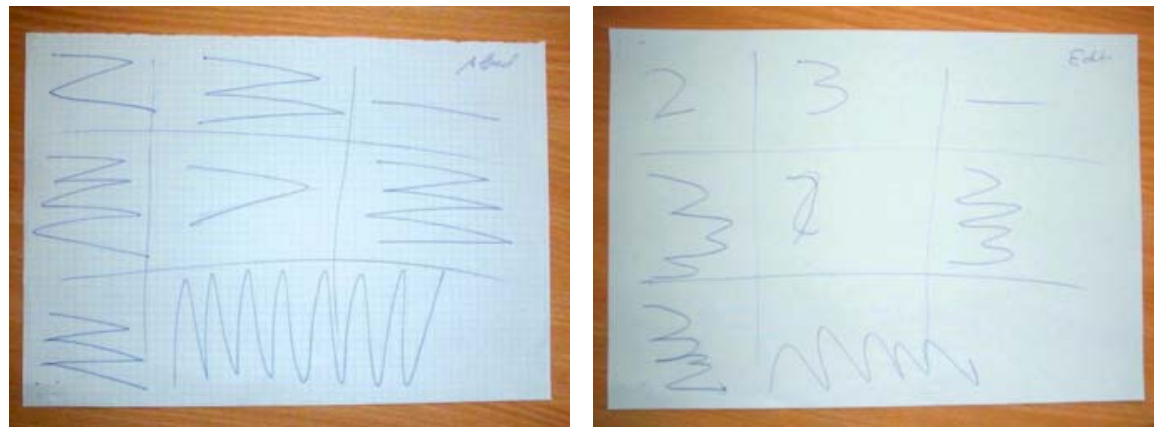

Figure 7. The presented movement (left) and the movement imitation of a 16-year-old with trisomy 21 (right).

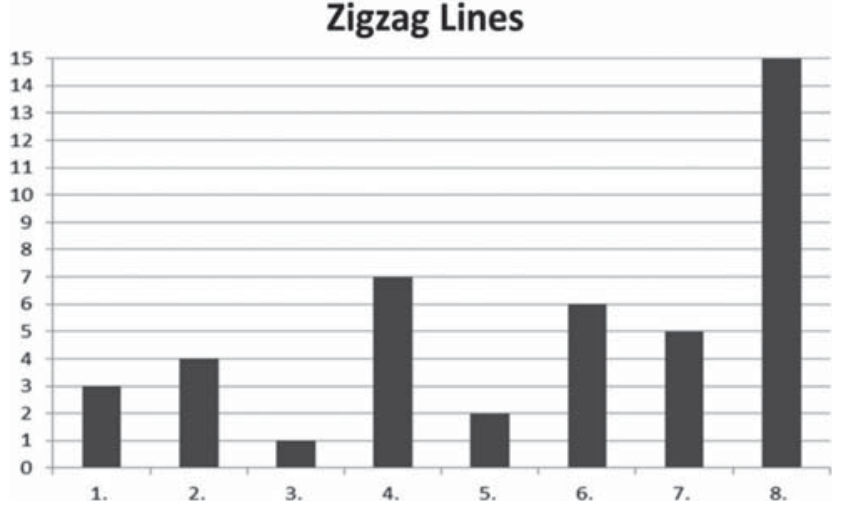

Figure 8. Change in difficulty level of the individual imitation experiments between one and seven elementary movements. Abscissa: Number of imitation experiments with different numbers of elementary movements for the Test Set dancing hands; ordinate: Number of elementary movements (level of difficulty).

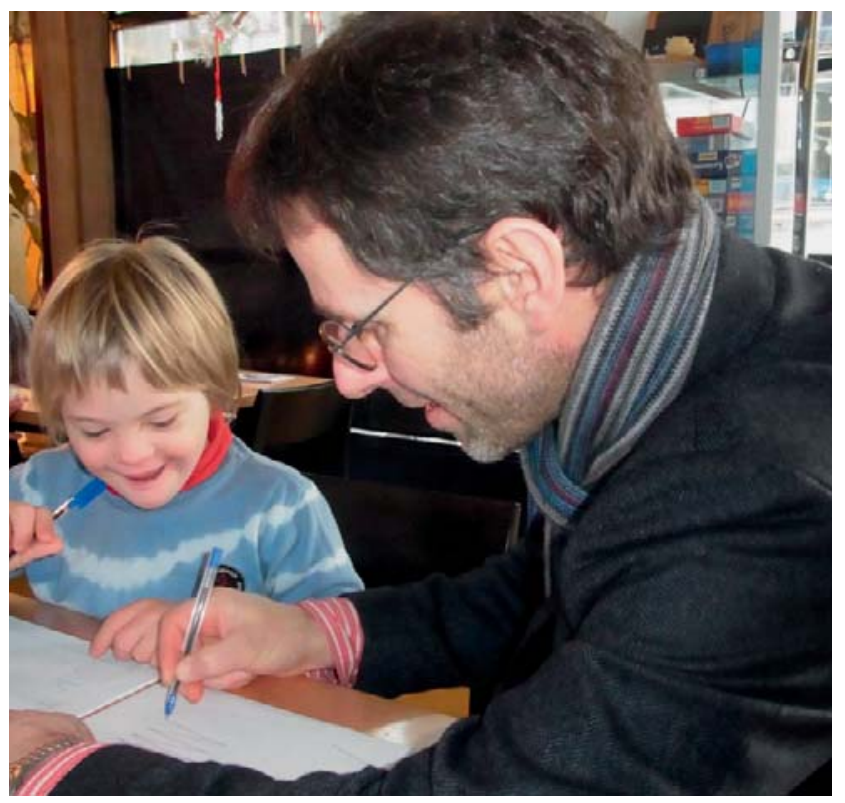

Figure 9 Imitation test (zigzag lines) with a 7-year-old boy from the test group.
21). The differing numbers of people in the individual test sets came about because participation was voluntary and had to be completed within a set amount of time (30 minutes total). 387 females and 316 males participated in these tests (see Table 2).

There were 183 participants in the preliminary testing phase (52 in the test group and 131 in the control group) and 520 in the main testing phase (261 in the test group and 259 in the control group). The age range of the test subjects in the main testing phase (Table 3) was 5-56 years (average: 18 years). In the control group, the age range was 6-55 years (average: 17 years). We therefore assume that the comparability of the test and control groups is assured.

The tests were carried out only after a preparatory instructional phase had ensured that the test procedure had been understood by the test subjects. Because there was no meaningful difference in difficulty between using the right or left hand in the experiments, both left-handed and right-handed persons took part in the tests.

The average value of the CPM score (Colored Progressive Matrices) of the participants with trisomy 21 (test group) is 32 (minimum: 30, maximum: 35 ). We carried out some experiments on concept of number development. Of the subjects without trisomy $21,40 \%$ already had fully developed concept of number in the age range of 4 to 5 years. The subjects with trisomy 21 only reached a similar value in the age range of 14 to 17 years. While the entire group without trisomy 21 has fully developed the concept of number by age 14, the group with trisomy 21 reached a peak of $45 \%$ in the age group 18+ years (Rieckmann, 2016, p. 160).

For the participants of the test group with fully developed concept of number, we performed the measurement of the visual attentional scope using a computer-based tachistoscope (cf. Zimpel, 2013, pp. 35-47) as follows: Sets of lines containing between 1 and 19 elements were shown on a computer screen, with each set visible for exactly 250 ms. The test subject is supposed to say as precisely as possible how many lines there are. In practice, it is not possible to mentally "group" the individual lines together in the brief moment that they are shown, much less count them. 
Table 1. Number of test participants and control groups

Test participants in the test series for proprioceptive attentional scope (total)

\begin{tabular}{llll}
\hline & Test group & Control group & Total \\
\hline Tested individuals & 316 & 387 & 703 \\
Dancing hands & 250 & 170 & 420 \\
Body percussion & 134 & 120 & 254 \\
Zigzag lines & 222 & 181 & 403 \\
\hline
\end{tabular}

Table 2. Number of male and female test subjects for all tests, broken down for the individual imitation experiments

\begin{tabular}{ll}
\hline & Number \\
\hline Tested individuals & 703 \\
- Number of male test subjects & 316 \\
- Number of female test subjects & 387 \\
Dancing hands & 420 \\
- Number of male test subjects & 205 \\
- Number of female test subjects & 215 \\
Body percussion & 254 \\
- Number of male test subjects & 104 \\
- Number of female test subjects & 150 \\
Zigzag lines & 403 \\
- Number of male test subjects & 162 \\
- Number of female test subjects & 241 \\
\hline
\end{tabular}

Table 3. Information about the ages of the people in the test and control groups.

\begin{tabular}{llll}
\hline $\begin{array}{l}\text { Age of test participants in the test series for proprioceptive atten- } \\
\text { tional scope (only main testing phase) }\end{array}$ & Test group & $\begin{array}{l}\text { Control } \\
\text { group }\end{array}$ & Total \\
\hline 1-9 years & 40 & 32 & 72 \\
$10-19$ years & 150 & 155 & 305 \\
$20-29$ years & 40 & 49 & 89 \\
$30-39$ years & 15 & 5 & 20 \\
$40-49$ years & 9 & 13 & 22 \\
$50-59$ years & 7 & 5 & 12 \\
Total & 261 & 259 & 520 \\
\hline
\end{tabular}

The scope of attention in the neurotypical control group is limited by the number four (subitizing limit). In the case of persons with trisomy 21 , this is significantly lower: two to three elements (Zimpel, 2016, p. 112-116).

For the participants of the test group without a fully developed concept of number, we performed other tests, such as the so-called "Monkey Ladder": Numbered boxes appear at different locations on the screen. The participants have to try to remember which number appears in which box. After a short time, the numbers disappear. The test subject is supposed to click the boxes in numerical sequence, beginning with the box where 1 was, then 2,3 , and so on.

More than half the neurotypical control group achieved more than four matches, but this was not once the case with persons with trisomy 21 . This result also suggests that persons with trisomy 21 have a smaller scope of visual attention (Zimpel, 2016, pp. 116-121).

In the next step, we checked the level of motoric development of the participants with trisomy 21 (test group). We tested everyday moving competence, like wrapping a cord around the wrist, tying knots and tying a loop, and the basic skills of throwing and catching a ball. There were no differences between the test and control groups in wrapping a cord around the wrist, in throwing a ball, or in catching a ball, but the differences were significant in tying knots and tying a loop.

This observation fits in with the registered highest levels of gene expression at basal ganglia (caudate nucleus, putamen) (Montoya et al., 2014, p. 154).

\section{Influence of Movement Experience on the Tests}

In order to keep the influence of movement experience as small as possible from the outset, we selected elementary movements for imitation: turning the hands over, knocking with the hands, stomping the feet, etc. There were at least seven different imitation experiments among the various tests which differed from one another in the number of elementary movements. The individual tasks to be imitated varied in difficulty level. The participants were presented with easy and difficult exercises alternating in as agreeable a way as possible in order to keep them from feeling overwhelmed. We therefore assume that the influence of movement experience on the tests is limited.

The preliminary tests, carried out using highly trained professionals as imitation learners ("movement professionals"), show that imitation performance is limited by attentional scope. As with computer-based tachistoscope measurements (Zimpel, 2013), the limit lies at the correct determination of four elements. Tests performed by nine adults without Down syndrome who had professional mo- 
vement backgrounds (dancers, musicians, performers, and physical-education teachers) confirmed this. The influence of professional movement experience on the imitation performance reaches a limit in both the test sets "dancing hands" (Figure 10) and "body percussion" (Figure 11) at the latest at five elementary movements.

The difference between the results of the 20 test subjects without special prior experience and the 9 with experience is not significant (Mann-Whitney U-test, Kolmogorov-Smirnov test).

In the Test Set "zigzag lines," in contrast, there were no observable differences between the professionals and non- professionals; in all cases, all seven elementary movements were reproduced correctly without any notable exceptions. We therefore assume that the differences between movement professionals and laypeople are slight.

\section{Statistical Analysis}

The number of successful imitation experiments in both the test and control groups are compared as independent random samples. Assumptions regarding the distribution (e.g., normal distribution) of the frequency of correct

Test set "dancing hands" for proprioceptive attentional scope (control group, preliminary tests)

Musicians, dancers, performers (5 subj.)

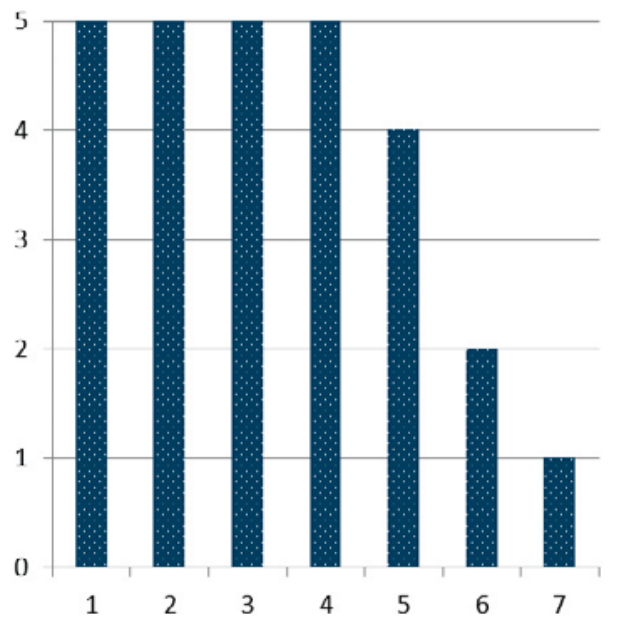

No particular previous experience (21 subj.)

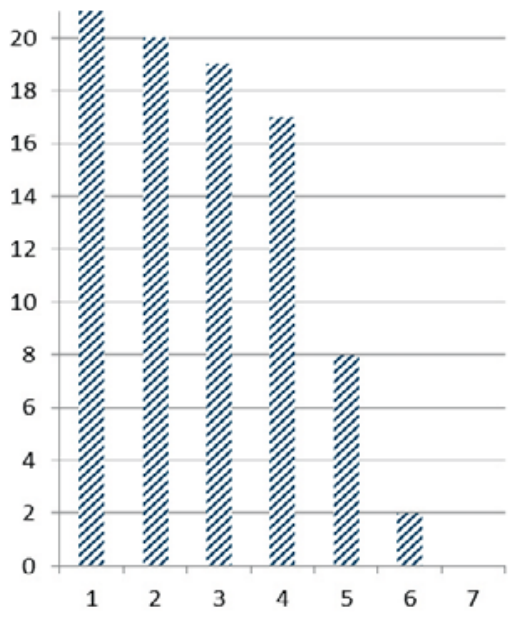

Figure 10. Comparison within the control group between persons with professional experience in music or movement and those without professional experience in music or movement for dancing hands. Abscissa: Level of complexity, ordinate: Number of test subjects. There was no significant difference between the groups (Wald-Wolfowitz run test, Mann-Whitney Utest, Kolmogorov-Smirnov test).

Test set "body percussion" for proprioceptive attentional scope (control group, preliminary tests)

Musicians, dancers, performers (8 subj.)

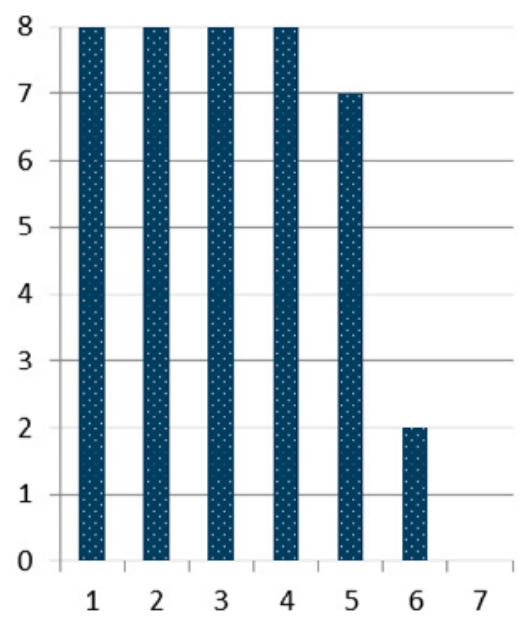

No particular previous experience (22 subj.)

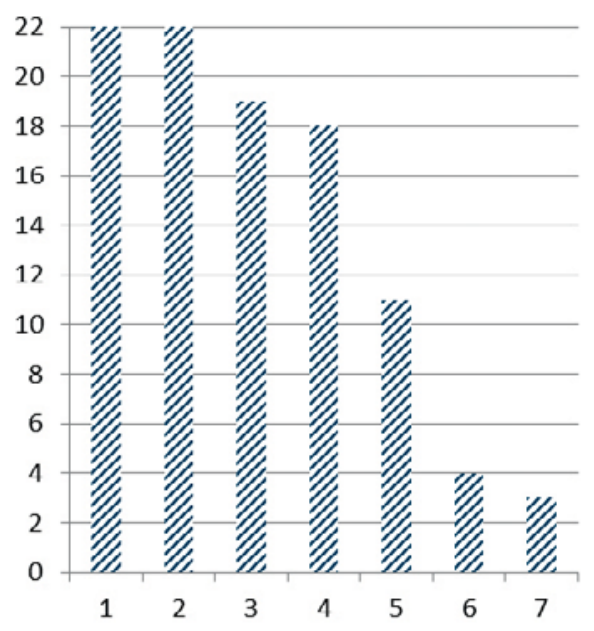

Figure 11. Comparison within the control group between persons with professional experience in music or movement and those without professional experience in music or movement for body percussion. Abscissa: Level of complexity, ordinate: Number of test subjects. There was no significant difference between the groups (Wald-Wolfowitz run test, MannWhitney U-test, Kolmogorov-Smirnov test). 
quantity recognition or estimates cannot be made. Here, are four tests are available: the Mann-Whitney U-test, the Wald-Wolfowitz run test, the Kolmogorov-Smirnov test, and the Moses test. The first three methods test the hypothesis whether both samples originate from the same population. The Moses test compares the breadth of both samples. Because the frequency of successful imitation experiments is based on an identical unit (correct or incorrect quantity), the level of measurement is also given for the Kolmogorov-Smirnov test. The rest of the testing methods, on the other hand, only require an ordinal scale.

\section{Results}

All three parts of the hypothesis were confirmed in this series of tests. The ability to exactly imitate a set of elementary movements following a complete presentation of the composite movement decreases more quickly in people in the test group (persons with trisomy 21) as the number of elementary movements increases than it does in people in the control group.

\section{Results of Test Set 1 (Body Percussion)}

Of the 92 total test subjects in the control group (without trisomy 21), all but two succeeded in imitating the presented movements in the individual experiments without any mistakes, which consisted of three elementary movements each. Of the 118 people in the test group (with trisomy 21), all were able to imitate the presented movements in the individual experiments consisting of one elementary movement without any mistakes (Figure 12). But as soon as two elementary movements were required, the test subjects began to experience difficulties in correctly imitating the presented movements. The differences between the test and control groups are highly significant. (The data of only one person in the test group could not be evaluated for the set of tests on body percussion because the prerequisite of cor- rectly imitating at least one elementary movement was not fulfilled. The data from the control group could all be evaluated.) These results confirm our hypothesis. The ability of persons with trisomy 21 to imitate is obviously dependent upon the number of presented elementary movements, which is also true for persons without this syndrome. For persons with trisomy 21, however, even movement sequences comprising only two to three movements limit their ability to imitate in a verifiable way, which is not the case for those without this syndrome. This could explain the difficulties faced by persons with trisomy 21 both in learning daily activities and when meeting school-related demands such as speaking, writing, and mathematics.

The ability to exactly imitate a set of elementary movements during the presentation of the composite movement decreases more quickly in people in the test group (with trisomy 21) as the number of elementary movements increases than it does in people in the control group.

\section{Results of Test Set 21 (Dancing Hands)}

The results of the Test Set with dancing hands are also highly significant. Of the 147 total test subjects in the control group (without trisomy 21), everyone succeeded in imitating the presented movements up to and including three elementary movements without any mistakes. Of the 208 people in the test group (with trisomy 21), everyone was able to imitate the presented movements in the individual experiments consisting of one elementary movement without any mistakes (Figure 13). The data could not be evaluated for 13 people in the test group for the set of tests on dancing hands because the prerequisite of correctly imitating at least one elementary movement was not fulfilled. The data from the control group could all be evaluated. The differences between the test and control groups are highly significant. It is clearly easier to imitate simultaneously than subsequently.

The ability to exactly imitate a set of elementary movements following the presentation of the composite movement, the result of which leaves a visible mark, decreases

Test set "body percussion" for proprioceptive attentional scope

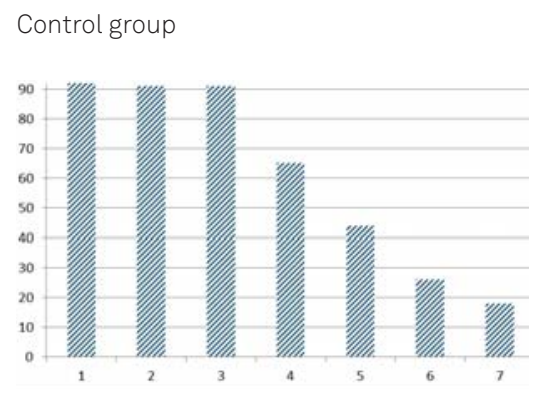

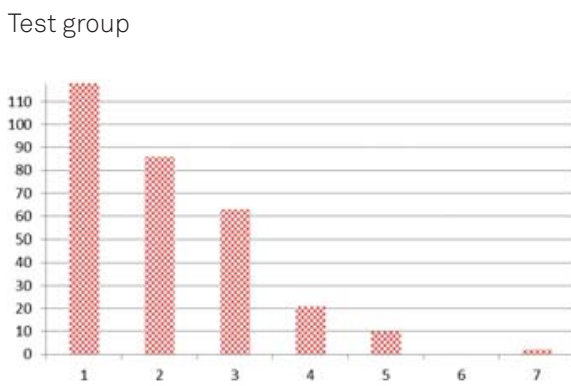

Figure 12. Results from the control and test groups for body percussion. Abscissa: Level of complexity; ordinate: Number of test subjects. The differences are statistically highly significant at a significance level of $p<.001$ (Moses test, Mann-Whitney U-test, Kolmogorov-Smirnov test). 
more quickly in people in the test group (with trisomy 21) as the number of elementary movements increases than it does in people in the control group.

\section{Results of Test Set 3 (Zigzag Lines)}

The results of the sets of tests with zigzag lines also show highly significant differences between the control and test groups. Of the 81 total participants in the control group, nearly everyone (with the exception of two) was able to reproduce the experiments from one to six elementary movements without making a mistake. In the test group, all 182 participants successfully performed the experiment with one elementary movement without making a mistake (Figure 14). But as soon as two elementary movements were required, the test subjects began to experience difficulties in correctly imitating the movements.

Although none of the test subjects counted out loud during the tests, quiet counting by the participants cannot be ruled out. Correspondingly, the positive results with larger quantities of lines reflect the ability to count along with the movement (Figure 15).

The additional experiment with 15 lines also revealed highly significant results. Of the 64 total participants in the control group, 45 had correct results, whereas in the test group, only 10 of the 165 total participants were able to perform the additional experiment with 15 elementary movements. This shows that the difficulties persons with trisomy 21 have with imitating are not dependent on the time needed to apprehend the task to be imitated. It also illustrates that the ability to exactly reproduce 15 lines decreases in persons without Down syndrome (Figure 16).

\section{Discussion}

\section{Kinesthetic Apraxia}

The kinesthetic attentional scope is also narrowed in persons with trisomy 21 . The results of the imitation study indicate that persons with trisomy 21 do in fact take a great deal of pleasure in imitating movements. But this can only be considered a strength, as described by several authors (Asperger, 1965; Down, 1866; König, 1959), in a limited way, because when confronted with complex movements, all of the test subjects with trisomy 21 clearly reached the limit of their abilities. They showed greater skill in compensating for their difficulties using strategies they came up with on their own (emulation).

Our explanation is that trisomy 21 is accompanied by kinesthetic dyspraxia. Kinesthesia is obviously subject to exactly the same limitations in persons with trisomy 21 as

Test set "dancing hands" for proprioceptive attentional scope

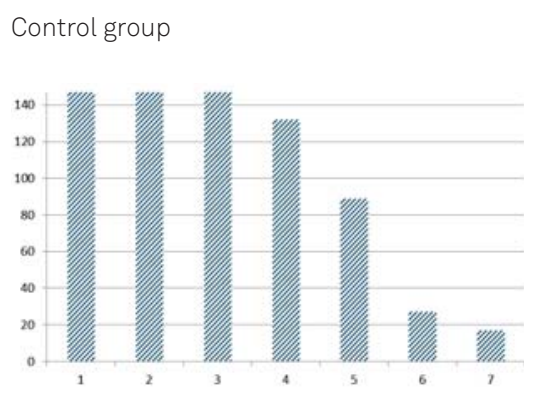

Test group

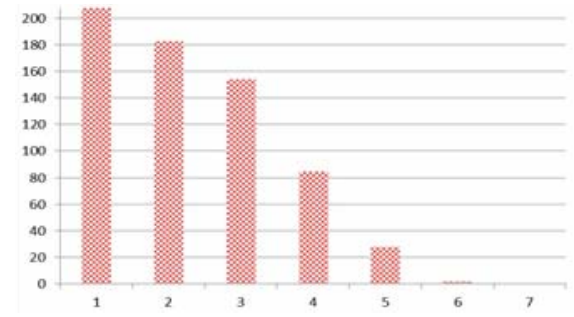

Figure 13. Results from the control and test groups for dancing hands. Abscissa: Level of complexity; ordinate: Number of test subjects. The differences are statistically highly significant at a significance level of $p<.001$ (Moses test, Mann-Whitney U-test, Kolmogorov-Smirnov test).

Test set "zigzag lines" for proprioceptive attentional scope

Control group

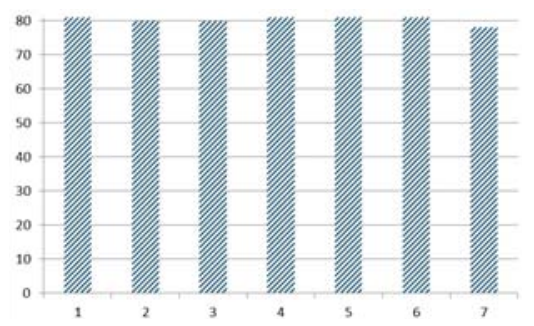

Test group

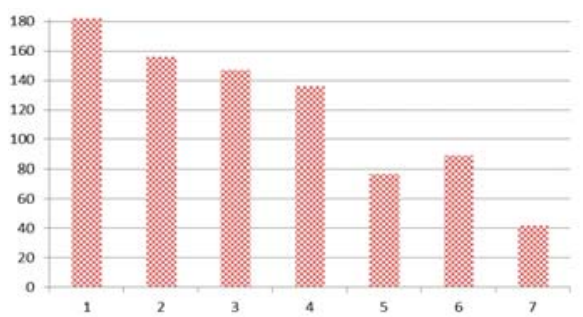

Figure 14. Results from the control and test groups for zigzag lines. Abscissa: Level of complexity; ordinate: Number of test subjects. The differences are statistically highly significant at a significance level of $\mathrm{p}<.001$ (Moses test, Mann-Whitney U-test, Kolmogorov-Smirnov test). 
the visual attentional scope, as measured with a tachistoscope, that Zimpel refers to as "simultaneous dysgnosia" in persons with trisomy 21 (Zimpel, 2013). In apraxia research the connection between a lack of ability to imitate and apraxia was made early on:

"Disorders in imitation have, since the beginning of apraxia research, been considered evidence that apraxia

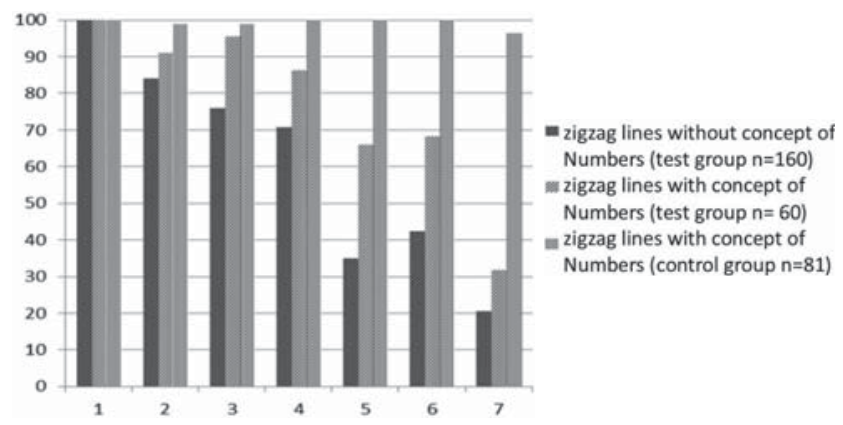

Figure 15. Influence of the presence of a concept of numbers on the test results of the test group with and without a concept of numbers as compared to the control group with a concept of numbers. Abscissa: Level of complexity; ordinate: Number of test subjects as a percentage. The differences are statistically highly significant at a significance level of $p<.001$ (Moses test, Mann-Whitney U-test).

Test set "zigzag lines" for proprioceptive attentional scope (15 elementary movements)
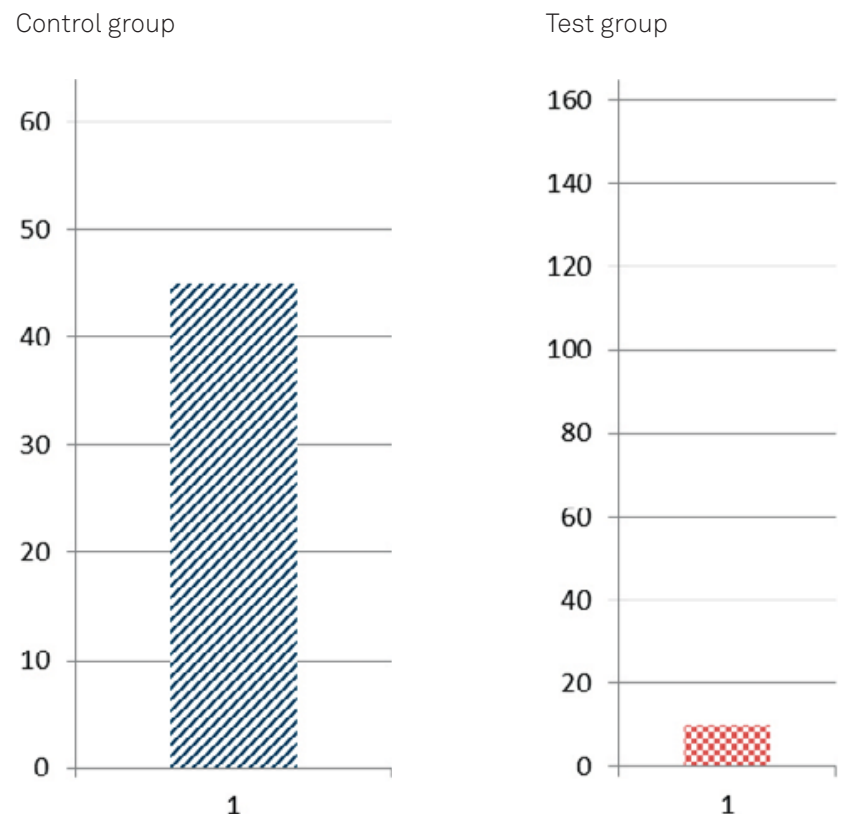

Figure 16. Results from the control and test groups for the additional experiment with zigzag lines. Abscissa: Level of complexity; ordinate: Number of test subjects. The differences are statistically highly significant at a significance level of $p<.001$ (Wald-Wolfowitz run test, Moses test, Mann-Whitney U-test, Kolmogorov-Smirnov test). is not simply the expression of an accompanying aphasia, but also affects nonverbal tasks" (Goldenberg, 2012, p. 404).

Apraxia and its less severe form, dyspraxia, are neither purely cognitive nor purely motor disorders. Rather, they involve "the boundary between cognition and motor function" (Goldenberg, 2011, p. 1). But what, exactly, does this mean?

Liepmann (1908, p. 18) answers this question as follows: "If the individual movements such as raising, lowering, bending, stretching, etc., the limbs are performed with an appropriate amount of strength and coordination, but the necessary combining of the movements to achieve the desired effect is not successful, then apraxia, or to a lesser degree dyspraxia, is present."

Apraxia research has found evidence that apraxia can be caused by a lesion on the left side of the parietal lobe, which then causes symptoms on both sides of the body (Goldenberg, 2011, p. 24; Liepmann, 1908, p. 21). Luria (1970, p. 221) calls this form of apraxia "kinesthetic apraxia." Normally, it results from damage to the postcentral sensory areas of the left (dominant) hemisphere (areas 1 , 2, 3, 5 according to Brodmann) and causes difficulties both on the contralateral and ipsilateral sides.

Apraxia does not necessarily accompany aphasia (cf. Goldenberg, 2011, p. 3) and, as Liepmann (1908, p. 23) found in his studies, is not caused by it: "They cannot even perform [a required movement] successfully when language was not used as the mode of communication."

Kinesthetic apraxia is not necessarily caused by visual processes either: "In the type of apraxia dealt with here, the visual apprehension of the external spatial coordinates (up, down, right, left) can remain intact; what is most disrupted is the correct structure of the kinesthetic impulses that regulate movement" (Luria, 1970, p. 221).

When a movement has been visually or verbally prompted, the information has to be processed in the parietal lobe so that the movement can be performed properly: "In this case, the movement can either be triggered by verbal prompts, which are primarily processed in Wernicke's speech area, or by the visual perception of a gesture to be imitated, which is analysed in the visual cortex" (Goldenberg, 2011, p. 7).

Goldenberg (2011, p. 6) places the source of limited action control in the parietal lobe: "[A lesion] in the parietal lobe [causes] an 'ideokinetic' apraxia in which the idea of the planned movement remains intact, but its translation into motor function is disrupted." Therefore, the more complex a movement sequence, the more difficult it will be for the apraxic person to imitate it correctly because "... the disintegration of the correct movement sequence poses the greatest difficulty that is characteristic of this form of apraxia" (Luria, 1970, p. 221). 


\section{Trisomy 21 in the Spectrum of Neurodiversity}

We speculate that, in the case of trisomy 21, the kinesthetic apraxia is connected with the simultandysgnosia (Zimpel, 2013). That is why we assume the kinesthetic apraxia is caused by different brain structures in the limbic system rather than by structures of the parietal lobe. But is there any evidence for this assumption?

This speculation fits in with genetic analysis. The genes DSCR3 and KCNJ6 of chromosome 21 control mainly the growth of sections CA1 and CA2 of the hippocampus. The influence of chromosome 21 on sections CA3 and CA4 of the hippocampus, in contrast, is very small (Montoya, 2014, p. 156).

The sections CA1 and CA3 are anatomically and functionally interesting for short-term memory. The Schaffer collaterals, which connect CA3 and CA1, contain special glutamate receptors (NMDA) that are involved in long-term potentiation (Kandel, 2011, pp. 699-707; Squire \& Kandel, 1999, p. 122), and they are important for ultra-short-term memory that connects the brain with the here and now. It contains what is currently the focus of attention. Kandel describes the focus of attention as what currently occupies the stream of thoughts (Squire \& Kandel, 1999, p. 92).

The Schaffer collaterals route signals to the CA1 region of the hippocampus. A single stimulus series of $100 \mathrm{~Hz}$ with a duration of $1 \mathrm{~s}$ initiates the early phase of LTP, which continues for about $2 \mathrm{~h}$ (short-term memory). Four stimulus series at 10-minute intervals trigger the late phase of LTP, which can last for more than $24 \mathrm{~h}$ (working memory) (Ibid., p. 158).

In addition, we assume that the smaller attentional scope of persons with trisomy 21 is part of a spectrum of neurodi- versity between persons with simultanagnosia and neurotypical people - and persons with autism spectrum disorder.

People with simultanagnosia, however, have a full field of vision. Their perception is not limited, but their attention: They can no longer perceive a point at the center of a circle because they can perceive only the circle or the point at the center marked with pencil (Luria, 1992, pp. 118-122). People with Williams-Beuren syndrome have similar problems (cf. Bellugi \& George, 2001, pp. 21-25).

In trisomy 21 , we therefore speak about simultandysgnosia, which is the limitation of the scope of attention to less than four objects concurrently. Our experiments confirmed this hypothesis in all subjects with trisomy 21 in the visual, acoustic, and haptic field of attention - and now in the kinaesthetic field, too.

Since subitizing by neurotypical people is, according to Trick und Pylyshyn (1994), a preattentional processing mechanism with strict capacity limitation on four chunks, we could extend the spectrum beyond neurotypical people in the other direction. It is known that persons with Asperger syndrome tend to have a greater attentional scope. The entire autism spectrum shows a confusing variety of capacity limitations of attention (Zimpel \& Hurtig-Bohn, 2016, pp. 245-248).

Adding the limitations together gives you a spectrum reminiscent a recurrent logistic function (Verhulst, 1845, 1847):

$\mathrm{f}(\mathrm{x})=\mathrm{ax}(1-\mathrm{x})$, where the $\mathrm{x}$-value starts with the initial value $x_{0}=0.1$ (Figure 17). The repeated application of quadratic functions to itself with increased a-value from 2 to nearly 4 leads to an eigenwert figure (Feigenbaum, 1980, 1984).

The following experiment forms the empirical basis for the recurrent mathematical modeling: GABA receptors in

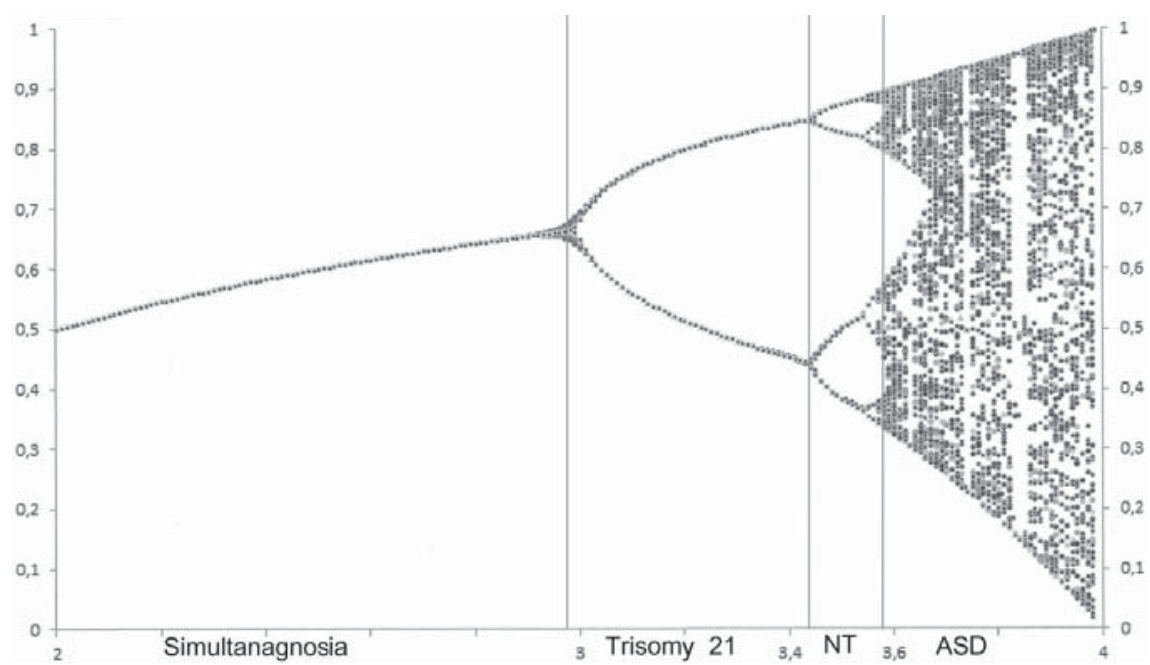

Figure 17. Adding the limitations of different syndromes (simultanagnosia, trisomy $21, \mathrm{NT}$ : neurotypical people, ASD: autism spectrum disorder) together gives you a spectrum reminiscent of the Verhulst function $f(x)=a x(1-x)$, where the value was increased from 2 to 4 . The Feigenbaum figure gives an overview of different fix points (eigenwerte). From left to right, the a-value of the function has been gradually increased from 2 to almost 4 . Each a-value corresponds to a different matrix of fixed points. 
the hippocampus of guinea pigs were inhibited with penicillin. The penicillin "clogged," figuratively speaking, the pores in the neurons through which GABA otherwise flows. Applying varying doses of penicillin to the cellular network of the hippocampus inhibits increasingly more GABA receptors. Low penicillin concentrations result in periodic patterns with a relatively low average pulse frequency. Membrane potential oscillations, which are no longer periodical and have a significantly increased average pulse frequency, finally appear at higher concentrations of penicillin. If you enter the values of membrane potential oscillations in a figure, you also get the pattern of a Feigenbaum figure (An der Heiden, 1991).

In our view, these indications speak for the theory that the attentional peculiarities of persons with trisomy 21 are a part of a whole spectrum of neurodiversity. However, many more investigations will be necessary to put these indicators together without gaps.

\section{Consequences for the Promotion of Persons with Trisomy 21}

The narrowed attentional scope causes learning difficulties. Not only is the smaller attentional scope a key cause of imitation difficulties in persons with trisomy 21 , it is clearly irrelevant along which sensory avenue the imitation takes place. The problems experienced by persons with trisomy 21 are therefore not (as often assumed) based on deficits in abstract thinking and acting that can be solved using sensual approaches (Kutscher, 1999, p. 142). They are in fact due to a smaller attentional scope.

The results of our study, however, give us an important argument in favor of projects like the following examples: at the Bar-Ilan University in Tel Aviv, Lifshitz-Vahav (2013; Lifshitz \& Tzuriel, 2004) prepared 26 students diagnosed with "mental disabilities" for a bachelor degree in educational science. The majority of them were living with trisomy 21. Melero (2003) reported similar positive experiences at the University of Málaga, where the famous actor Pablo Pineda (2014, pp. 26-33) with trisomy 21 got his university degree.

People with trisomy 21 thus lead their lives under altered neurological conditions. A not insignificant part of the neurological differences can be explained by the deviations in their attentional scope. It must be acknowledged, however, that the diverse characteristics of trisomy 21 cannot be traced back alone to the change in a few genes.

The higher gene dosage leads to countless changes with an exponentially greater number of possibilities that can, of course, also be influenced by environmental conditions. For this reason, the overall picture for people living under the conditions of trisomy 21 also depends largely on environ- mental conditions. Social integration and respect for their needs as well as a democratic learning atmosphere are essential conditions for their overall mental development.

A meta-analysis covering the years from 1970-2010 of international experiences with the integration and inclusion of persons with trisomy 21 came to the conclusion that adolescents with trisomy 21 are well accepted by their peers in regular classes (De Graaf, van Hove, \& Haveman, 2012). Their ability to learn and their language development benefit especially from inclusion.

"Full inclusion means that special needs students can and should be educated, with appropriate support, in the same settings as their other peers. This, claim the advocates, leads to increased expectations by teachers, more peer interaction, more learning, and greater self-esteem" (Hattie, 2009, p. 96).

This meta-analysis of learning success referred to small but positive advantages for mainstream over special classes, and more specifically for achievement and for social/ personality outcomes. It also found similar effects for those classified mentally retarded than learning disabled across various grades (Hattie, 2009).

The results of these evidence-based studies also corroborate our practical experiences and tests in three ways:

1. Mental development (including language ability and learning ability) is dependent upon the learning environment. Providing the proper learning environment, however, runs up against structural limitations at special-needs schools.

2. Imitation learning in respectful social relationships in inclusive classrooms does not suffice. Persons with trisomy 21 require sensitive educational observation and design.

3. Experience the ability to help others is just as important as the ability to accept and find help (cf. Zimpel, 2012, p. 12).

\section{References}

An der Heiden, U. (1991). Der Organismus als selbstherstellendes dynamisches System. In K. Zänker (Ed.), Kommunikationsnetzwerke im Körper. Psychoneuroimmunologie. Aspekte einer neuen Wissenschaftsdisziplin (pp. 143-154). Heidelberg: Spektrum.

Asperger, H. (1965). Heilpädagogik - Einführung in die Psychopathologie des Kindes für Ärzte, Lehrer, Psychologen, Richter und Fürsorgerinnen (4th ed.). Vienna, New York: Springer.

Bellugi, U., \& George, M.S. (2001). Journey from cognition to brain to gene. Cambridge, MA: MIT.

De Graaf, G., van Hove, G., \& Haveman, M. (2012). Effects of regular versus special school placement on students with Down syndrom: A systematic review of studies. In A. van den Bosch \& $E$. Dubois (Eds.), New developments in Down syndrom research (pp. 45-86). Hauppauge, NY: Nova.

Down, L. (1866). Observation on an ethnic classification of idiots. London: Churchill \& Sons. 
Feigenbaum, M.J. (1980). The metric universal properties of period doubling difurcations and the spectrum for a route to turbulence. Annals of the New York Academy of Sciences, 357, 330-336.

Feigenbaum, M.J. (1984). Universal behavior in nonlinear systems. In B. L. Hao (Ed.), Chaos (pp. 49-84). Bristol, UK: Adam Hilger.

Goldenberg, G. (2011). Apraxien. Göttingen: Hogrefe.

Goldenberg, G. (2012). Apraxie. In H.O. Karnath \& P. Thier (Eds.) Kognitive Neurowissenschaften (pp. 403-414). Berlin, Heidelberg: Springer-Verlag.

Hattie, J. (2009). Visible learning: A synthesis of over 800 metaanalyses relating to achievement. London: Taylor \& Francis.

Kandel, E.R. (2011). Zelluläre Grundlagen von Lernen und Gedächtnis. In E.R. Kandel, J.H. Schwartz, \& T.M. Jessell (Eds.), Neurowissenschaften. Eine Einführung (pp. 685-714). Heidelberg: Spektrum.

König, K. (1959). Der Mongolismus - Erscheinungsbild und Herkunft. Stuttgart: Hippokrates.

Kutscher, J. (1999). Kinder und Jugendliche mit Trisomie 21 - Förderung und Wahrnehmung ihrer Entwicklung auf dem Weg zur Identität. In E. Wilken (Ed.), Neue Perspektiven für Menschen mit Down-Syndrom (138-142). Erlangen: Selbsthilfegruppe für Menschen mit Down-Syndrom und ihre Freunde e.V.

Lejeune, J., Gautier, M., \& Turpin, R. (1959). Study of somatic chromosomes from 9 mongoloid children. Comptes Rendus Hebdomadaires des Seances de l Academie des Sciences, 248, 1721-1722.

Liepmann, H. (1908). Drei Aufsätze aus dem Apraxiegebiet. Berlin: Karger.

Lifshitz, H., \& Tzuriel, D. (2004). Durability of effects of instrumental enrichment in adults with intellectual disabilities. Journal of Cognitive Education and Psychology, 3, 297-322.

Lifshitz-Vahav, H. (2013). Otzmot - Innovative program for students with intellectual disabilities: First-of-its-kind in Israel. BIU TODAY The Bar-Ilan University Magazine, 2-3.

Luria, A.R. (1970). Die höheren kortikalen Funktionen des Menschen und ihre Störungen bei örtlichen Hirnschädigungen. Berlin:Verlag der Wissenschaften.

Luria, A. R. (1992). Das Gehirn in Aktion. Reinbek: Rowohlt.

Melero, M. L. (2003). El proyecto Roma: una experiencia de educación en valores. Málaga: Ediciones Aljibe, S. L.

Montoya, J.C., Fajardo, D., Peña, A., Sánchez, A., Domínguez, M.C. Satizábal, J.M., \& García-Vallejo, F. (2014). Global differential expression of genes located in the Down syndrome critical region in normal human brain. Colombia Médica, 45, 154-161.

Pineda, P. (2014). Herausforderung Lernen. Ein Plädoyer für die Vielfalt. Zirndorf: G\&S.

Rieckmann, T. (2016). Cognitive development and mathematics. In A.F. Zimpel (Ed.), Trisomy 21 - What we can learn from persons with Down syndrome. 2000 people and their neuropsychological findings (pp. 158-174). Bristol, CN: Vandenhoeck \& Ruprecht.

Röhm, A. (2016). Imitation and Motorlearning. In A. F. Zimpel (Ed.), Trisomy 21 - What we can learn from persons with Down syndrome. 2000 people and their neuropsychological findings (pp. 135-146). Göttingen:Vandenhoeck \& Ruprecht.

Squire, L.R., \& Kandel, E.R. (1999). Gedächtnis. Die Natur des Erinnerns. Heidelberg: Spektrum.

Trick, L. M., \& Pylyshyn, Z.W. (1994). Why are small and large numbers enumerated differently? A limited-capacity preattentive stage in vision. Psychological Review, 101(1), 80-102.

Verhulst, P.F. (1845). Recherches mathématiques sur la loi d'accroissement de la population. Nouveaux mémoires de l'Académie royale des sciences et belles-lettres de Bruxelles, $18,1-41$.

Verhulst, P.F. (1847). Deuxième mémoire sur la loi d'accroissement de la population. Mémoires de l'Académie Imperiale et Royale des Sciences et Belles-Lettres de Bruxelles, 20, 1-32.

Zimpel, A., \& Hurtig-Bohn, K. (2016). Autismusspektrum und Neurodiversitätsforschung. Praxis Sprache, 4, 245-250.

Zimpel, A. F. (2012): Einander helfen - Der Weg zur inklusiven Lernkultur. Göttingen: Vandenhoeck \& Ruprecht.

Zimpel, A.F. (2013). Studien zur Verbesserung des Verständnisses von Lernschwierigkeiten bei Trisomie 21 - Bericht über die Ergebnisse einer Voruntersuchung. Zeitschrift für Neuropsychologie, 24, 35-47.

Zimpel, A. F. (2016). Trisomy 21 - What we can learn from persons with Down syndrome. 2000 people and their neuropsychological findings. Bristol, CN: Vandenhoeck \& Ruprecht.

Manuscript submitted: 13.03.2015

Accepted after revision: 16.04.2018

Conflict of interest: None

\section{Prof. Dr. habil. André Frank Zimpel}

Universität Hamburg

Fakultät für Erziehungswissenschaft (EW 2)

Schulpädagogik, Sozialpädagogik,

Behindertenpädagogik und Psychologie

in Erziehung und Unterricht (EW 2)

Sedanstr. 19

20146 Hamburg

Deutschland

Andre.Zimpel@uni-hamburg.de 